\title{
MANUFACTURING OF A VISCOMETER FOR MONITORING OIL CONTENT IN POLLUTED WATER
}

\author{
R. J. M. Souza ${ }^{1,2}$, A. König ${ }^{2}$ \\ ${ }^{1}$ Instituto Federal do Rio Grande do Norte e ${ }^{2}$ PPG Recursos Naturais - Universidade Federal de Campina Grande \\ roberto.monteiro@ifrn.edu.br
}

Artigo submetido em setembro/2012 e aceito em dezembro/2012

\begin{abstract}
Petroleum activities have been frequently associated to environmental damage due to occurrence of oil spill in worldwide sea waters. In addition to this problem it must be considered that many non-petrol companies process oil derivatives and discharge their rejection in rivers, accidentally or purposely. The monitoring of water contamination is usually carried out by government agencies, as well as by private committees. Therefore, population rarely becomes totally aware of the facts concerning oil contamination in rivers and seas, unless these committees and agencies publish accurate data about it. Social participation is an important demand as to promoting politically correct environmental management, however
\end{abstract}

it is necessary to provide instrumental support to achieve this aim. In this work it is proposed a "do it yourself" viscometer designed to estimate oil rate in bodies of water contaminated by ship spill or industry discharge. The instrument includes, among other components: one electric drill, one DC -6 volt motor and one multimeter. Results show their reliability on the basis that the instrument allows a procedure which is capable of measuring viscosity in immiscible solutions unlike conventional viscometers. The viscometer is suggested as a tool for Rapid Assessment Program, which can meet social technology availability in order to cover qualitative and quantitative parameters.

KEY-WORDS: water monitoring, oil pollution, rotary viscometer, environmental volunteering. 


\section{MANUFACTURING OF A VISCOMETER FOR MONITORING OIL CONTENT IN POLLUTED WATER}

\section{INTRODUCTION}

The practice of environmental preservation, far from being a ubiquitous reality, has not yet reached vast social layers, and it must be noted that diffusion of ecological consciousness is often impaired by the predominant concept that State government by itself is responsible for every initiative to prevent, to interfere, or to eliminate factors that can endanger environment quality. Even when corporations assume the responsibility in marine pollution, their environmentalism is not able to substitute government intervention in managing marine environment, as Garrod and Whitmarsh (2000) said on their article entitled "The economics of marine pollution control".

Government issues appear to be most easily assimilated by social actors who expect effective solutions on the ground that participative management has not yet reached a high level of consciousness, so it leads to a transfer of ecological responsibility.

Petroleum activities have become a concern of worldwide interest since decades of oil spill occurrences from tankers, some of them transporting more than five hundred ton of crude oil, have been causing environmental damage in overseas operation throughout the world, as discussed, for instance, by Ulrich (2011) on her study of social impact of the gulf oil disaster, of which amount of damage will take years to be accurately assessed.

UNESCO/WHO/UNEP (1996) publication warns against the danger in neglecting the importance of nature conservation by oil corporations and government, as said: "Due to the high ecological risk associated with oil extraction, transportation, refining and use, mineral oil is considered a priority pollutant and its determination is important for assessments related to these activities".

Nevertheless, people at large appear to assimilate nature degradation as a trivial matter for human survival despite the fact that media has been systematically playing a relevant role as an incisive announcer of ecological disasters.

Although media does not exhaust its ability to explore environment degradation, nature by itself does not respond successfully to injury whatsoever indefinitely imposed by human activities, mainly due to its incapability to recover spontaneously after repetitive damage when it reaches its critical point. It occurs because nature's resilience has its own restraints. An example for reason of clearness lies upon the short cycle of life and death in heavily polluted rivers of which self-recovery capability has collapsed to an irreversible point. This problem is a challenge to overcome in sustainable development policy.

It has been claimed that environmental participative management is a suitable way to achieve effective results in ecology-based economic development. However there are not HOLOS, Ano 28, Vol 6 
accurate parameters to establish whose responsibility on every decision must be accounted in order to settle for the right direction at planning and execution strategies in such mode of management, since society and industry usually cope with a conflict of interests.

O'Faircheallaigh (2010) points out an important aspect concerning leadership when he mentions that "public participation raises issues regarding control over decision making that are not subject to resolution, but must be managed through ongoing processes of negotiation". On that account, an alternative way to allow society's actors to participate, though indirectly, in effective ecological policy is by self-engagement in autonomous monitoring of environment quality, despite their presumed lack of professional methods and expensive instruments specifically designed for that purpose.

In fact, some usual measurements in water monitoring do not demand for an academic knowledge, neither all required instrumental resources need sophisticated investments. It is possible to obtain consistent data from certain physical or chemical properties of water by using simple techniques as well as low-price easily acquired material, as it is the case of viscosity measurement procedure with the use of autonomous resources which will be discussed on the basis of social technology.

In addition, current trends of environmental assessment, such as Rapid Assessment Program (RAP), created in 1990, can serve as a platform to introduce quantified information techniques for reinforcement of that strategy which is focused on species inventory survey methods. A deeper scope can be possibly achieved by filling eventual gaps related to the lack of quantitative issues, with the addition of environmental monitoring "do it yourself" (DIY) technology.

Bernard (2008) points out some recommendations about the RAP taken place in the Tumucumaque Mountains National Park, Amapá, Brazil. One of his most incisive issues is particularly apposite to the present proposal, in his own words: "New initiatives focused on the study of abiotic characteristics must also be supported and stimulated, including the characterization and mapping of the chemical composition in the main water courses, and characterization of the geologic, geo-chemical and climatic processes ..." What can be detached from the above statement is basically the emphasis for assessment innovation, therefore, it leads to a search for new accessible monitoring tools that can add useful information on RAP so it can set forth a wide explanatory framework about ecosystems in imminent danger.

Obviously, DIY instruments must share in common the so called social technology, as it is proposed here: a low cost-technically feasible apparatus that can be manufactured by any citizen who is motivated by ecological matters.

RAP and social technology together must be able to encourage an intensive social pursuit for environmental research, taking advantage of their peculiar characteristics which 
complement one another in order to expand both monitoring and assessment knowledge towards society's actors.

As formerly pointed out, the knowledge of ecosystem processes added to autonomous tools for environmental monitoring can lead social actors to pledge for significant changes in participative management policy, seeking for better life quality in every threatened bioma. In this vein, Rapid Assessment Program aided by social technology points in that direction as an advantageous methodological approach to environmental monitoring from the moment that society gets included as management participants.

Basic education should play a major role in consolidating individual consciousness about citizen's compromise on behalf to environmental conservation, but as long as this way of thinking is seen as a cliché, there is a lot to be done for nature's sake. Students at early age could have their creativity stimulated by searching responses, yet imaginative, for giving vent to their skills and potential as social multipliers of the knowledge necessary to properly manage nature's quality of life.

Environmental autonomous monitoring thus emerges as an optional strategy for social inclusion in natural resource participative management.

\section{MAIN SCOPE}

Considering that oil pollution in water is a matter of extreme importance, since water quality legislation covers critical oil rates in polluted water according to UNESCO/WHO/UNEP (1996): "The permissible concentration of mineral oil and petroleum products in water depends on the intended use of the water. The recommended maximum concentrations for drinking water supplies and fisheries protection are generally between 0.01 and $0.1 \mathrm{mg} / \mathrm{l}$. Concentrations of $0.3 \mathrm{mg} / \mathrm{l}$ or more of crude oil can cause toxic effects in freshwater fish".

Thus the scope of this work is to make possible to common citizen a self-equipment that can enable autonomous water monitoring in cases of water pollution by mineral oils.

\section{PARAMETERS OF STUDY}

Water monitoring parameter assessment according to APHA (1999), generally include:

- Temperature

- $\mathrm{pH}$

- Conductivity

- Dissolved Oxygen

- Nitrogen 
- Phosphorous

Although viscosity is not a standardized parameter for water quality monitoring, it is considered a very important property in analyzing mineral oils, as mentioned by Sattarina et al (2007).

It is a matter of fact that bodies of water polluted by oil spreading from ship spills or industry discharges cannot be entirely evaluated without taking into account the variation of viscosity as a basic physical property. However, there is not hitherto an apparatus designed to measure viscosity in non-miscible fluids, such as it occurs in a water-oil mixture. Thus, one would not have another choice unless measuring viscosity of each non-miscible fluid separately by accomplishing the usual laboratory procedure routine.

One important observation about oil content in water bodies is that, unlike laboratory common situations where fluid samples remain static, the oil-water heterogeneous mixture in polluted water is agitated, not least, because of natural dynamics derived from ocean current or river flow, or even due to wind effect. Yet water and oil do not mix chemically, because oil is insoluble in water, they can combine to form a kind of emulsion in specific cases, and that emulsion might function as an inhibitor to biotic processes, the same way as oil film on water surface can block air and light input necessary to maintain marine life. These aspects must not be ignored, since many samples are collected for further analysis which should be accomplished at conditions indeed similar to those ones found in situ.

\section{MATERIAL AND METHODS}

Measurement of water-oil dynamic viscosity by simulating natural conditions is made possible by means of a low cost technology which can be feasible to common citizens, as following explained.

The working principle of the DIY rotary viscometer is based upon the electromagnetic induction produced by a 6-volt motor shaft rotation due to friction between fluid and propeller inside the sample flask, which is turned by the drilling machine operation. For this reason, another appropriate name for the instrument would be: electro inductive rotary viscometer. The apparatus was developed by the author with the purpose of autonomous environmental monitoring in rivers.

It is necessary to point out that the concept involved in manufacturing a rotary viscometer by oneself is liable to few different options of mounting concerning material and basic skills necessary for an amateur initiative. Therefore, the instrument described here is basically a half-dozen main piece assembly, and its production must take into account that a simple but precise calibration needs to be carried out to assure significant results, which 
demands preliminary measurements made with distilled water and a couple of specific lubricating oils, such as SAE 40, SAE 90 or similar.

Electronic work sheets are helpful to proceed experimental result analisys, because logarithmic regression allows a reliable representation for relating viscosity variation versus oil content in the oil-water mixture, as it will be discussed later.

In order to manufacture an electro inductive rotary viscometer (Figure 1) it was necessary to acquire the following components:

- one electric drill (300-400 w);

- one small flask (suggested: plastic baking powder flask with threaded cap);

- one DC - 6 volt motor;

- two aluminum rulers (300 $\mathrm{mm}$ long);

- two steel worm drive hose clamps (diameters about $25 \mathrm{~mm}$ and $50 \mathrm{~mm}$ );

- one propeller (suggested: two ice cream plastic spoons glued to each other);

- three steel screws(diameter about $3 \mathrm{~mm}$ ) plus butterfly nuts and washers;

- one steel screw (diameter $9 \mathrm{~mm}$ x length $45 \mathrm{~mm}$ ) plus nut and washer.

- one multimeter (also called multitester).

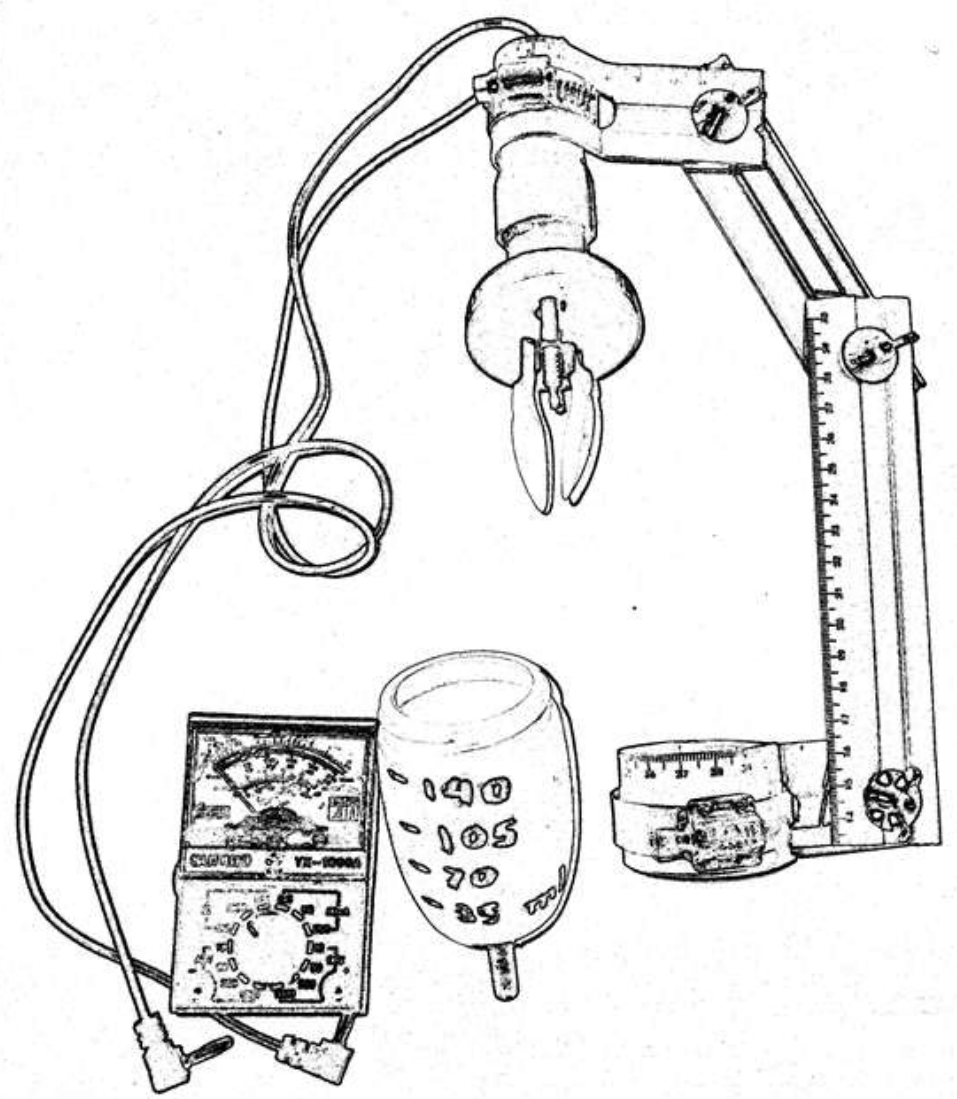


Figure 1 - Basic components to produce a DIY electro inductive rotary viscometer, from bottom left clockwise: multimeter, terminal cords, DC 6 volt, aluminum, worm drive hose and plastic flask. Photo edited by the author.

Considering that a small propeller is the only component that might not be quite easily available in department stores, it is suggested to proceed a simple assembly by gluing with epoxy instant adhesive two small plastic spoons cut down to half size at an angle of 15 o (relative to vertical) on the plastic adapter bushing to be inserted by the shaft of the 6 volt motor. Both spoons must face each other on their concavities. The shaft adapter bushing can be obtained from one of the two plastic terminals removed from the multimeter. Figure 2 shows how some of these elements were assembled.

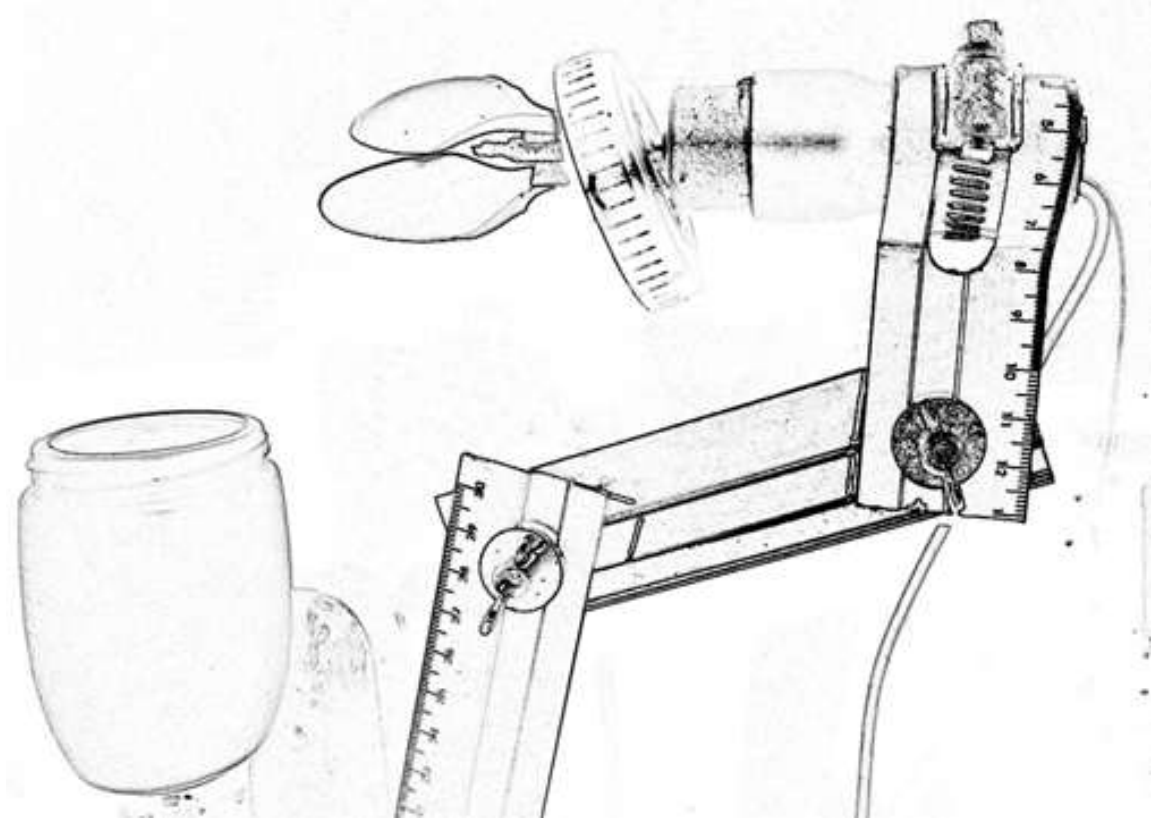

Figure 2 - Detail of propeller and flask articulation. Photo edited by the author.

The flask containing fluid sample is coupled to the electric drill by means of a screw which is hermetically attached to its bottom so the chuck rotation causes the fluid to turn likewise inside the flask, and experience proved that the higher the fluid viscosity the faster the propeller will rotate. That is why the flask would rather have a thick plastic bottom, because it must be bored to receive a $45 \mathrm{~mm}$ long screw to be coupled into the electric drill chuck.

Both aluminum rulers are cut in two pieces, each of them at a proportion of $2 / 5$ and $3 / 5$ their length for every pair. The two smaller pieces are curved at one of their edges to hold the 6 volt motor and the electric drill cylinder head with the use of steel worm drive hose clamps, while the flat surfaces of the rulers are pivoted among themselves with the use of screw-butterfly nut attachments. This system resulted in an articulated apparatus finely fitted to keep both propeller shaft and flask vertical center totally aligned in order to preserve 
rotation balance of the drilling machine. It must be noted that each worm drive hose clamp must pass through an orifice bored in the bent aluminum ruler so it can be tightly fastened.

The multimeter must be set to the minimum level of amperage scale, so that any slight variation of current intensity produced by the motor can be read. It is recommended the use of analog multimeter, since a digital one is often unable to keep steady values as experience proved.

For the purpose of experiment, the drilling machine ought to be firmly set upwards by means of one steel worm drive hose clamp that can be attached to a chair stile (for convenience), and the rotation frequency is stablished at $420 \mathrm{rpm}$ (this figure stands for suggestion, although higher speed can be technically allowed). Figure 3 shows the recommended position for using the apparatus.

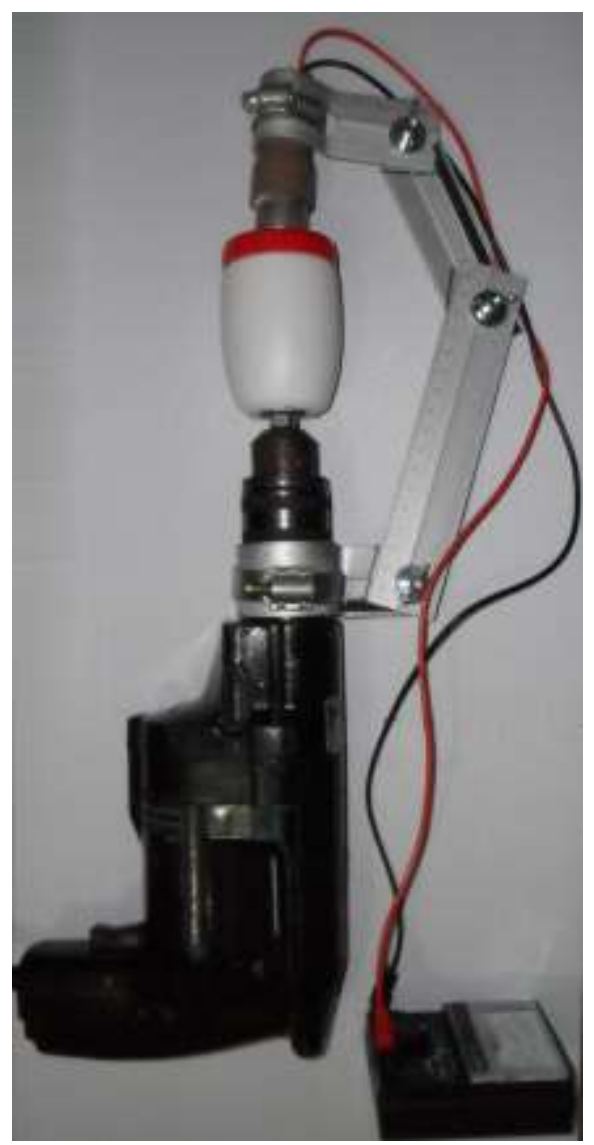

Figure 3 - Rotary viscometer assembled on a drilling machine set upwards. Multimeter is shown down at right. Photo by the author.

The experiment was carried out at five different mixture conditions of oil content in distilled water for purpose of calibration:

- pure water;

- $25 \%$ of oil in water; 
- $50 \%$ of oil in water;

- $75 \%$ of oil in water;

- $100 \%$ of oil.

Theoretically, it was expected a direct proportionality between oil-water viscosity and amperage measured by multimeter as for the same rotation frequency, given that viscosity makes the fluid to resist flow (Kinky, 1982), thus shear stress originated would transfer momentum to the propeller causing the motor shaft to spin and so it produces electro induction proportional to fluid viscosity.

Experimentation took place according to conditions described, that is, five different samples, and results confirmed theory.

\section{RESULTS AND DISCUSSION}

Environmental conditions of experiment were kept at $25^{\circ} \mathrm{C}$ air temperature at $1 \mathrm{~atm}$, and the apparatus was positioned vertically with level ruler comparison.

The results for every sample tested in the DIY rotary viscometer are shown in figure 4.

\section{Oil content in water $x$ Current intensity}

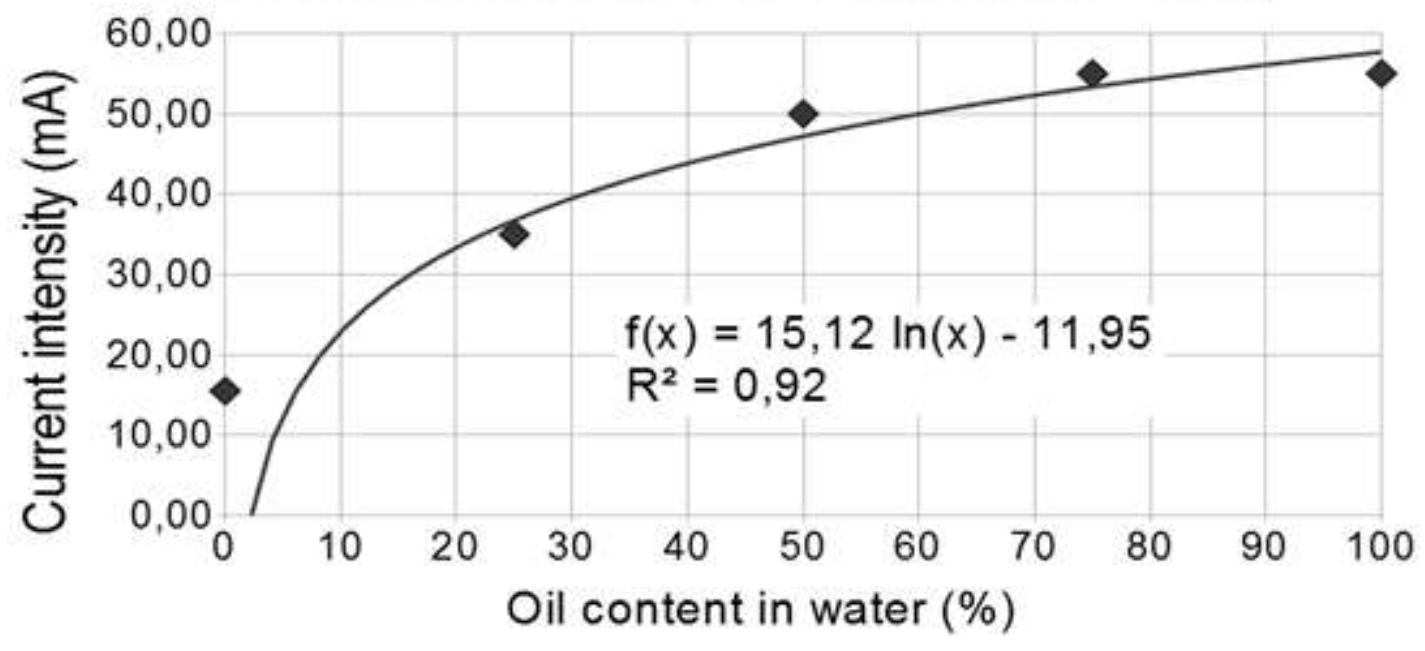

Figure 4 - Tendency curve approximation by logarithmic function to represent experiment results with a coefficient of determination estimated in $\mathbf{0 . 9 2}$. (Source: the author).

According to the logarithmic function obtained from figure 4, it was possible to estimate oil viscosity by comparison to another curve plotted taking into consideration the proportionality between oil content in water and dynamic viscosity, since amperage measured by multimeter can be converted into centiPoise (miliPascal-second) as both pure water and SAE 40 oil have their viscosities known at $25^{\circ} \mathrm{C}$, which figures are: $0.89 \mathrm{cP}$ (absolute) and 300 cSt (kinematic), as shown in figures 5 and 6. 


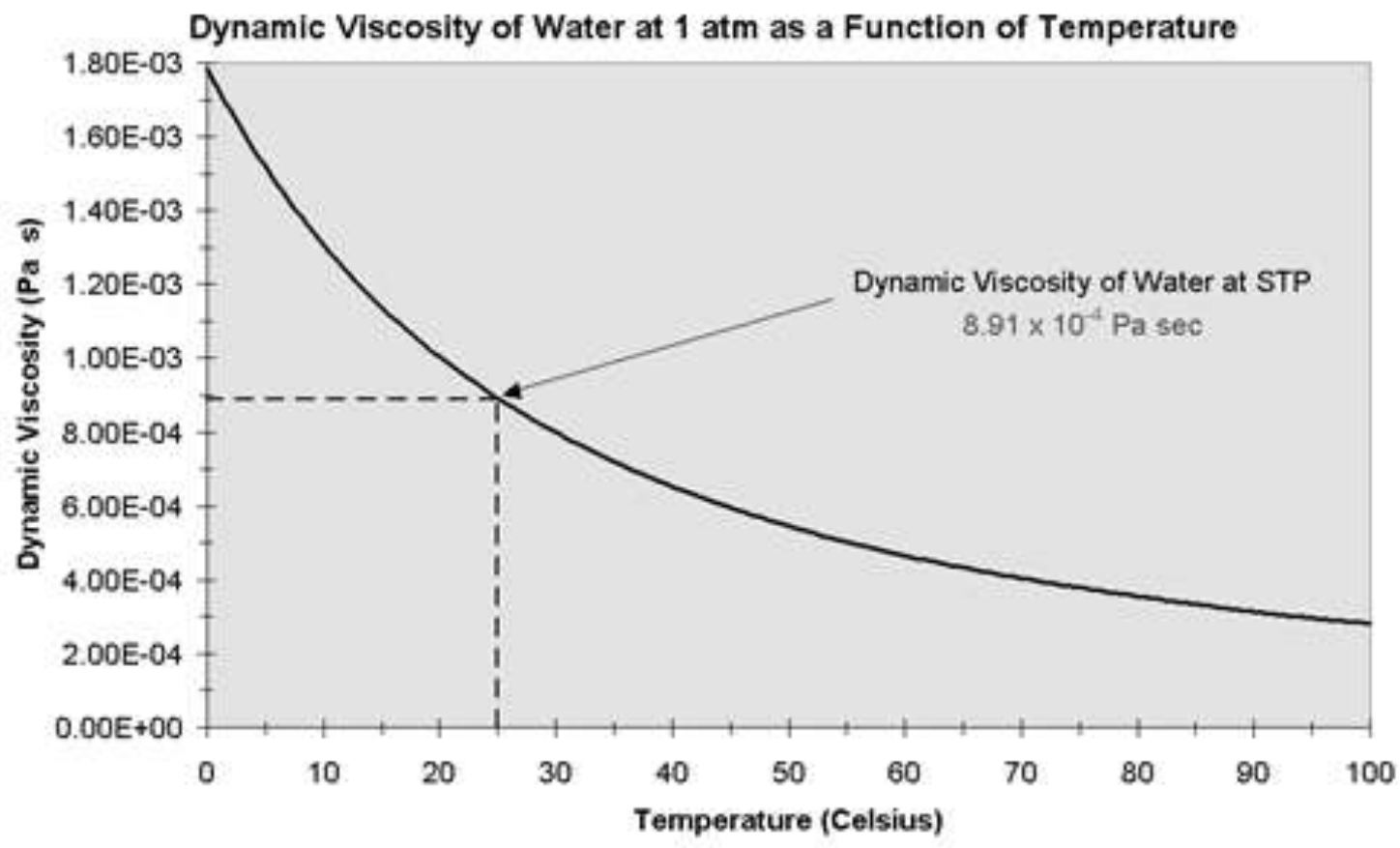

Figure 5 - Dynamic viscosity of water at $25^{\circ} \mathrm{C}$. (Excerpt from: Kinnas, 2010).

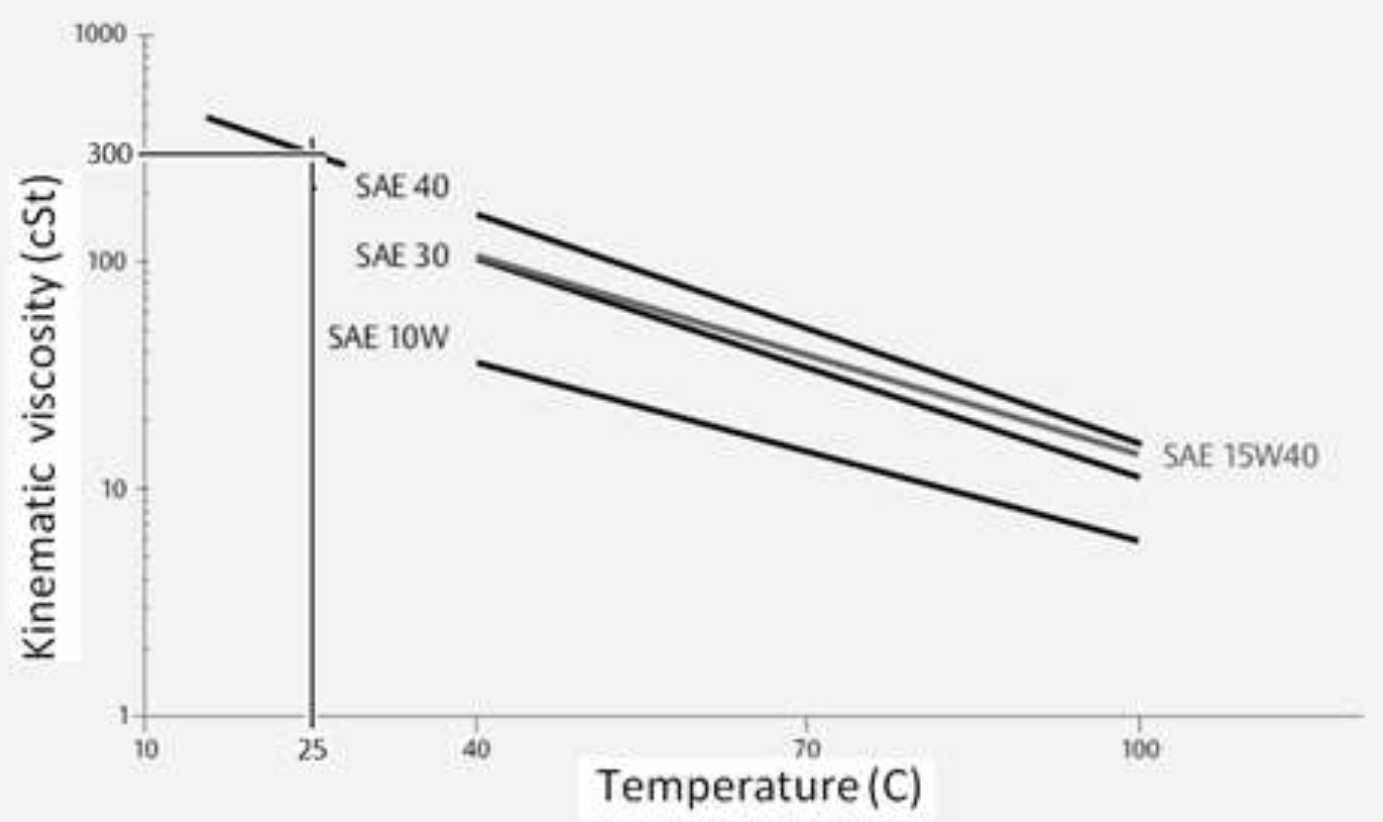

Figure 6 - Kinematic viscosity of lubricating oils, pointing out SAE 40 at 25 C. (adapted from: Chevron Corporation, 2005).

It should be noted that oil viscosity is given in cSt units, which refers to kinematic viscosity (property that is the ratio of dynamic viscosity to density), so SAE 40 oil dynamic viscosity can be computed by multiplying 300 to its density (0.90), resulting $270 \mathrm{cP}$.

Other mathematical functions could be used to describe the phenomenum of electro inductive current produced by propeller rotation due to fluid viscosity, inclusively a polinomial HOLOS, Ano 28, Vol 6 
of third degree that would give better approximation. In any case, the logarithmic equation is the most simple representation to be handled experimentally, even by a layman capable to operate $\ln (x)$ and $e^{x}$ functions in a scientific calculator, which justifies its choice.

Given that inferior and superior limits in both charts must be kept proportinal to each other, a useful rule of thumb was to divide the upmost dynamic viscosity (270) at $100 \%$ oil content by the upmost amperage (55) pertinent to that condition, which resulted in a approximate factor of 4.9. This factor was adopted to all points except for the initial one, which was experimentally known, i.e. $0.89 \mathrm{cP}$. Thus, applying this factor to the remaining experimentally assessed results, it was achieved a set of data to plot the new chart as shown in figure 7.

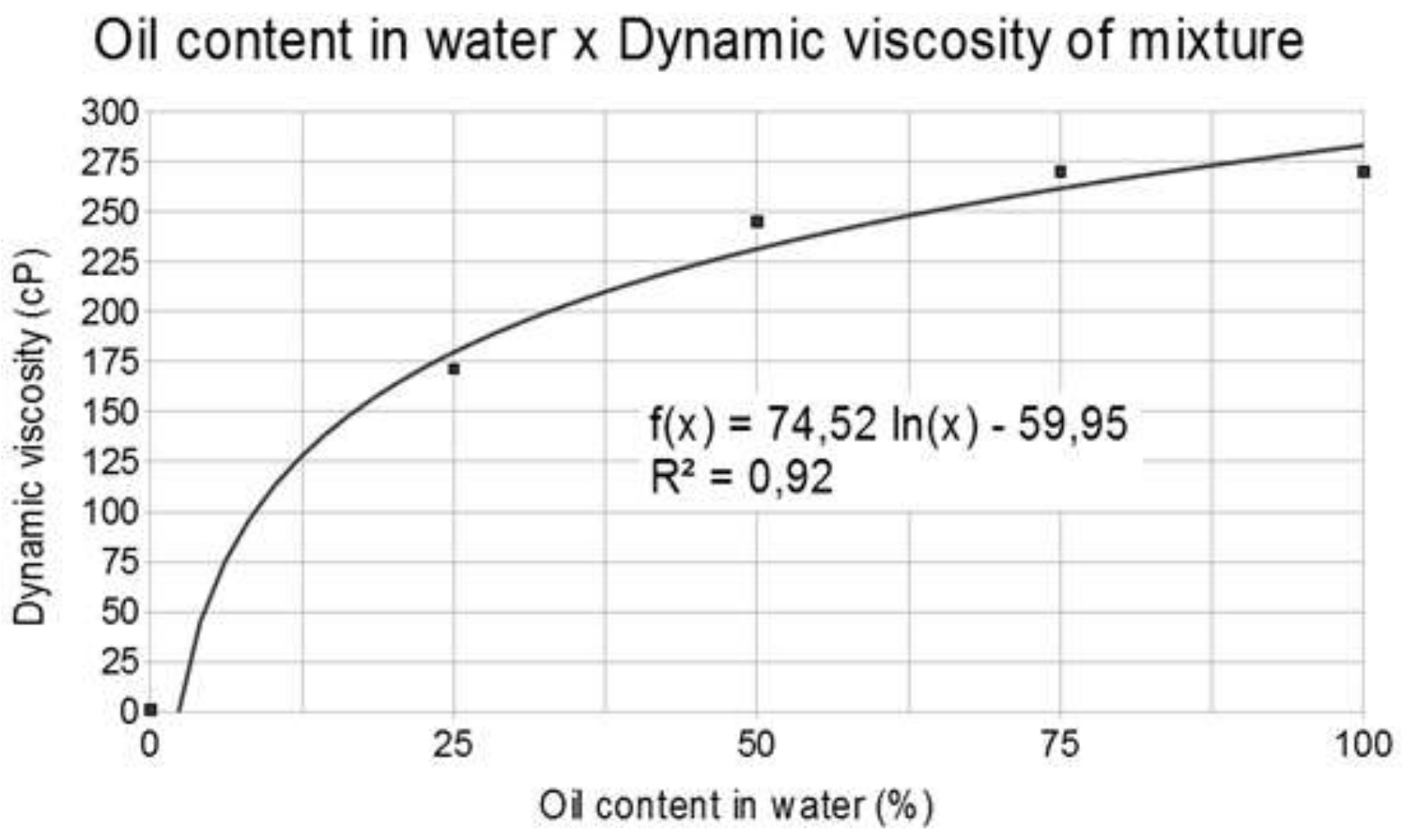

Figure 7 - Tendency curve approximation by logarithmic function to represent viscosity estimates according to experiment results multiplied by a factor of 4.9 with a coefficient of determination estimated in 0.92 . (Source: the author).

It follows from figure 7 that oil content figures smaller than $2.2 \%$ (approximately) would give incoerent results despite the high coeficient of determination, what assures that the experiment proposed is quite proper to be recommended for a wide range of pollution levels above $3 \%$ of oil rate in water.

It must be pointed out that a coefficient of determination equal to 0.92 accounts for a high level of reciprocal proportionality of dispersion regarding each other variables, i.e. how HOLOS, Ano 28, Vol 6 
much variation in dinamyc viscosity of the oil-water mixture can be explained by variation in oil content, thus providing a reliable analytical model as a prediction tool to be handled by river basin committee agents, for instance.

Regarding the resolution of DIY rotary viscometer, it can be estimated according to multimeter scale (shown in figure 8).

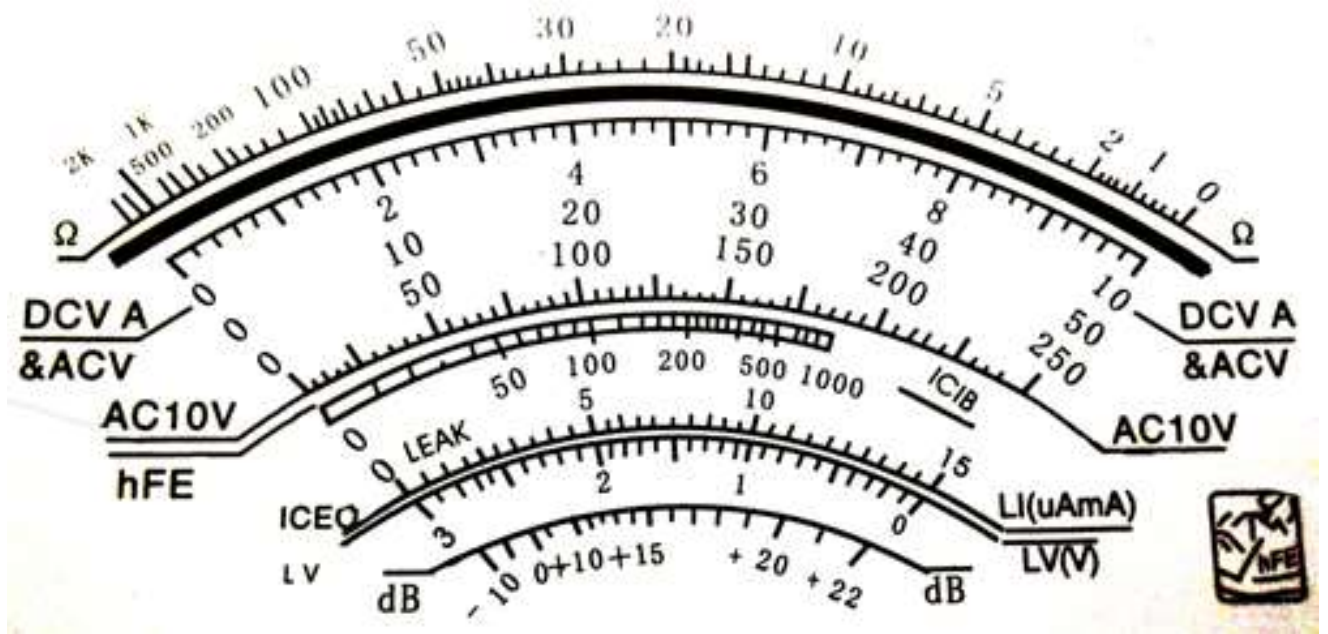

Figure 8 - Scales of a typical multimeter. (Photo by the author).

As shown in figure 8, the scale for DCV A \& ACV (selected for measurement according to the level of amperage produced by the viscometer propeller rotation due to fluid viscosity inside the rotary flask coupled to the electric drill) has multiple options from 0 to 10,50 or 250. These scales were considered when reading the intensity current values for every range selected, starting from 0 to $25 \mathrm{~mA}$, and so on. In this case, it was noted that every scale division corresponds to $0.5 \mathrm{~mA}$, i.e. the scale resolution could be assumed as $0.25 \mathrm{~mA}$ (since any intermediate position of the indicator pointer can be read as half distance of scale division). Thus, using a difference of $0.25 \mathrm{~mA}$, the equation expressed in diagram 1 gave:

$f(x)=15.12 \ln (x)-11.95$

equation (1)

$0.25=15.12 \ln (x)-11.95$

$12.2=15.12 \ln (x)$

$\ln (x)=0.807$

$\mathrm{e}^{\ln (\mathrm{x})}=\mathrm{e}^{0.807}$

$x=2.24$

Therefore, the resolution for oil content in percentual terms can be described as circa $2.24 \%$, which responds for a visocisity resolution that can be evaluated by equation expressed in diagram 4 , as follows. 
$f(x)=74.52 \ln (x)-59.95$

equation (2)

$f(x)=74.52 \ln (2.24)-59.95$

$f(x)=0.149 \sim 0.15$

Summing up, the resolution associated to dynamic viscosity can be assumed as circa $0.15 \mathrm{cP}$. Such resolution can also be interpreted as $0.05 \%$ of difference between water and SAE 40 oil viscosities at $25^{\circ} \mathrm{C}$, and it lies upon the measurement reliability, given that this concept is associated to consistency of measure repetibility, which showed to be highly dependable for a three-cycle measurement repetition.

The manufacturing of a DIY viscometer, as shown, demanded only non-expensive items and basic skills. An estimate for cost of material amounted about US\$ 50.00 (fifty US dollars), which is likely accessible for autonomous researcher prepared to invest in water quality monitoring, or a professional interested in promote quantitative assessment together with Rapid Assessment Program.

Obviously this DIY rotary viscometer concept opens several other possibilities to further designs by improving some of its features, among them, the propeller dimensions in order to be more slightly affected by fluid rotation, so that wider ranges can be achieved in multimeter scales. Although it was designed for measurement of viscosity in immiscible fluids mixture, it can be securely applied to homogeneous mixtures or greases even for nonenvironmental purpose.

An example of application for the rotary electro inductive viscometer calibrated with data given in figures 4 and 7 is explained as follows.

\section{Example}

Suppose an oil spill from a tank ship spreads out so it reaches the river bank of a given region. A researcher intends to estimate oil content in a sample of water collected at specific points by using his DIY rotary viscometer (already calibrated by fractional sample method described previously), then he gets an average reading of $28 \mathrm{~mA}$ at $25^{\circ} \mathrm{C}$ (assumed as standard temperature), so he applies the equation for current intensity. As an instance it will be used equation (1), obtained from figure 4, which gives:

$$
\begin{aligned}
& f(x)=15.12 \ln (x)-11.95 \\
& 28=15.12 \ln (x)-11.95 \\
& 28+11.95=0.15 \ln (x)
\end{aligned}
$$$$
39.95=15.12 \ln (x)
$$ 
$\ln (x)=2.64$

$e^{\ln (x)}=e^{2.64}$

$x=14.0$

Thus, there is circa $14 \% \pm 1.12 \%$ of oil in water for the sample assessed, according to resolution previously estimated (note that uncertainty is computed as half resolution). However, it is necessary to consider that this proportion is estimated on the basis of SAE 40 oil, so the viscometer must be previously calibrated regarding different types of oil, in order to provide a set of equations to be used properly according to the current situation.

The oil content figure can be used to estimate dynamic viscosity by means of equation (2), obtained from figure 7 , which gives in this case:

$f(x)=74.52 \ln (x)-59.95$

equation (4)

$f(x)=74.52 \ln (14)-59.95$

$f(x)=136.7$

Therefore, dynamic viscosity for the sample in question (containing 14\% SAE 40 oil and $86 \%$ water) is circa $137 c P \pm 0,075 \mathrm{CP}$ (uncertainty figure according to half resolution previously estimated), that is nearly the same dynamic viscosity found in totally pure SAE 30 oil at $30 \mathrm{C}$ temperature (see figure 6).

\section{CONCLUSION}

It is possible to manufacture a "do it yourself" reliable instrument designed to assess level of water contamination by oil, as proved by means of the electro inductive rotary viscometer tested in this work.

The instrument proposed here, apart from its functional principles and features, denotes a sense of urgency for social technology in order to promote strong environmental participative management, since it can stimulate as well as inspire researchers and students to develop accessible tools and methods in order to spread out a volunteer initiative for common citizens interested in carrying out ecological assessment by themselves.

\section{REFERENCES}

1. APHA - American Public Health Association. Standard Methods for the Examination of Water and Wastewater. Part 400.733 p. 1999. 
2. BERNARD, E. Inventários Biológicos Rápidos no Parque Nacional Montanhas do Tumucumaque - Rapid Biological Inventories in the Tumucumaque Mountains National Park, Amapá, Brazil. RAP Bulletin of Biological Assessment 48. Conservation International, Arlington, VA.151 p. 2008.

3. CHEVRON CORPORATION 2005. Fundamentos de lubrificação - Texaco. 74 p. Available at: <http://www.joinville.ifsc.edu.br/ antoniobrito/Manutencao\%20Mecanica/Fundamentos \%20de\%20Lubrificação\%20-\%20Texaco.pdf>. Accessed in: September. 2011.

4. GARROD, B.; WHITMARSH, D. The economics of marine pollution control. Marine Pollution Bulletin. Volume 30, Issue 6, June, Pages 365-371. 1995.

5. KINNAS, S.A. Elementary Mechanics of Fluids. The University of Texas at Austin. Course available at: <http://www.ce.utexas.edu/prof/kinnas/319lab/>. Released in: 2010.

6. KINSKY, R. Applied Fluid Mechanics. Sydney. McGraw-Hill.182 p. 1982.

7. O'FAIRCHEALLAIGH, C. Public participation and environmental impact assessment: Purposes, implications, and lessons for public policy making. Environmental Impact Assessment Review. Volume 30, Issue 1, January. Pages 19-27. 2010.

8. SATTARINA, M.; MODARRESI, H.; BAYATA, M.; TEYMORIA, M. NEW VISCOSITY CORRELATIONS FOR DEAD CRUDE OILS. Petroleum \& Coal 49 (2), 33-39. 2007.

9. UNITED NATIONS EDUCATIONAL, SCIENTIFIC AND CULTURAL ORGANIZATION (UNESCO) / WORLD HEALTH ORGANIZATION (WHO) / UNITED NATIONS ENVIRONMENT PROGRAMME (UNEP). Water Quality Assessments - A Guide to Use of Biota, Sediments and Water in Environmental Monitoring. 2nd edition. London. 651 p. 1996.

10. ULRICH, J.D. The Social Impact of the Gulf Oil Disaster - Diverging Views From Communities in Florida and Louisiana. Carsey Institute. ISSUE BRIEF NO. 25. 6p. SPRING 2011. 